\title{
CORRIGENDUM
}

\section{'At home it's just so much easier to be yourself': older adults' perceptions of ageing in place - CORRIGENDUM}

\section{DAMIEN STONES and JUDITH GULLIFER}

doi: 10.1017/So144686X14001214, published online by Cambridge University Press o1 December 2014.

The acknowledgement section of this article cited the support of Villa Maria Society to the original research project carried out by the first (DS) and second (JG) authors in 2010. However, this general acknowledgement failed to adequately distinguish the collaboration of Villa Maria Society staff member Ms Annie Lanyan, with the first author (DS) in related workplace research activities, that were reflected in the revised analysis of the original research report necessary for final publication as a journal article. Accordingly, this notice corrects the omission by the first author (DS), in acknowledging the contribution of Ms Annie Lanyan to the journal article as a third, joint author.

\section{Reference}

Stones, D. and Gullifer, J. 'At home it's just so much easier to be yourself': older adults' perceptions of ageing in place. Ageing $\mathcal{E}$ Society, published by Cambridge University Press, o1 December 2014. doi: 10.1017/So144686X14001214 